\title{
Breeding rootstocks for Prunus species: Advances in genetic and genomics of peach and cherry as a model
}

\author{
Verónica Guajardo $^{1 *}$, Patricio Hinrichsen ${ }^{2}$, and Carlos Muñoz ${ }^{3}$
}

\begin{abstract}
Prunus rootstock is an important choice in optimizing productivity of grafted cultivars. Nevertheless, many Prunus rootstocks are notoriously intolerant to hypoxia which is caused by waterlogging and/or heavy soils. There is no available information to help select Prunus rootstocks that are tolerant to stress conditions such as root hypoxia caused by excess moisture. Information from genetic maps has demonstrated a high level of synteny among Prunus species, and this suggests that they all share a similar genomic structure. It should be possible to identify the genetic determinants involved in tolerance to hypoxia and other traits in Prunus rootstocks by applying methods to identify regions of the genome involved in the expression of important traits; these have been developed mainly in peach which is the model species for the genus. Molecular markers that are tightly linked to major genes would be useful in marker-assisted selection (MAS) to optimize new rootstock selection. This article provides insight on the advances in the development of molecular markers, genetic maps, and gene identification in Prunus, mainly in peach; the aim is to provide a general approach for identifying the genetic determinants of hypoxia stress in rootstocks.
\end{abstract}

Key words: Hypoxia, linkage map, marker-assisted selection, molecular markers, family Rosaceae.

\section{INTRODUCTION}

Rosaceae is a numerous and economically important family of angiosperms. It is divided into three subfamilies: Amygdaloideae, Dryadoideae, and Rosoideae (Potter et al., 2007). The genus Prunus includes important fruit crops such as peach (P. persica $(\mathrm{L}$.$) Batsch, 2 n=16)$, sweet cherry $(P$. avium (L.) L., $2 n=16)$, sour cherry $(P$. cerasus $\mathrm{L} ., 2 n=4 \mathrm{x}=32)$, apricot $(P$. armeniaca $\mathrm{L} ., 2 n=$ 16), almond (P. dulcis (Mill.) D.A. Webb, $2 n=16$ ), prune (P. domestica L., $2 n=6 \mathrm{x}=48)$, and plum $(P$. salicina Lindl., $2 n=16)$. Cultivars of these species are normally grafted onto a compatible rootstock to restrict scion vigor, provide better anchorage, or allow better adaptation to biotic and abiotic stresses that are characteristic of certain soils or climates. Most currently available rootstocks come from interspecific crosses and the rootstock/scion combination varies depending on the compatibility among

${ }^{1}$ Centro de Estudios Avanzados en Fruticultura (CEAF), Camino Las Parcelas 882, sector Los Choapinos, Rengo, Chile.

*Corresponding author (vguajardo@ceaf.cl).

${ }^{2}$ Instituto de Investigaciones Agropecuarias, INIA La Platina, Santa Rosa 11610, La Pintana, Santiago, Chile.

${ }^{3}$ Universidad de Chile, Facultad de Ciencias Agronómicas, Santa Rosa 11315, La Pintana, Santiago, Chile.

Received: 5 January 2015.

Accepted: 25 April 2015.

doi:10.4067/S0718-58392015000300003 species. For example, plum rootstocks mainly originate from $P$. domestica L., P. insititia L., and $P$. cerasifera Ehrh.; they can also be used for peach, plum, apricot, and almond. Interspecific peach $\times$ almond hybrids $(P$. persica $\times P$. dulcis) are mainly used as rootstock for peach and almond. Cherry rootstocks come from $P$. cerasus and $P$. cerasifera, which are used for sweet and sour cherry (Moreno, 2004).

Much of the available information about the performance of different rootstocks is empirical data from many trials carried out at different locations. Detection and analysis of the underlying genetic variation can lead to the understanding of the molecular bases of the biological phenomena that distinguish them, such as tolerance or susceptibility to a given type of stress. The development of markers to help select individuals with traits that are complex to evaluate should speed up the development of new rootstocks that are resistant or tolerant to multiple diseases or stresses.

The agronomic definition of stress related to waterlogging tolerance is that of maintaining relatively high productivity under flooded as compared with nonflooded conditions (Setter and Waters, 2003). This definition suggests that a waterlogging-tolerant genotype can have a tolerance mechanism associated with an escape response to the anaerobic condition. These escape mechanisms include induced dormancy or reduced growth during the waterlogging period and rapid recovery 
after stress is removed (Setter and Waters, 2003). One of the most economical methods to reduce damage caused by waterlogging, or other conditions that induce hypoxia or anoxia in soils, is to introduce tolerance in existing cultivars through breeding. For this, anoxia-tolerant germplasm is needed, as well as appropriate methods to evaluate individuals of interest. Perhaps it would be even more useful to understand the genetic basis of anoxia tolerance (Zhou, 2010). Identifying genes involved in the expression of a character and the development of associated molecular markers is useful for the accurate and early selection of tolerant individuals in a breeding program. However, molecular markers must fulfill two main requisites to be functional: (i) to have polymorphic sequences within the species and (ii) to have functional polymorphisms that affect the plant phenotype with a high correlation between DNA polymorphism and the character of interest (Polidoros et al., 2009).

The objective of this review was to provide insight on the advances in the development of molecular markers, genetic maps, and gene identification in Prunus, mainly peach which is the model species for the genus; also to provide a general approach to identify the genetic determinants of hypoxic stress tolerance because the method that will be used should be similar to methods used for other traits of agronomic interest.

\section{THE GENOMICS OF Prunus}

Genetic improvement methods in Prunus cultivars and rootstocks have changed very little over the last $50 \mathrm{yr}$ (Dirlewanger et al., 2004), but they still exhibit some differences. In contrast to the development of new scion cultivars, in which evaluating each generation can require 2 or 5 yr, evaluation cycles in rootstock programs can require 7 to $10 \mathrm{yr}$ (Beckman and Lang, 2003). However, enhanced methodologies and new technologies have provided important tools for improving evaluation systems and selection of individuals. Marker-assisted selection (MAS) is a promising strategy for improving classical breeding methods (Knapp, 1998). It is based on information from genetic linkage maps that allow the detection of so-called quantitative trait loci (QTLs). Linkage maps also provide an understanding of the genetic bases of economically important traits. Markerassisted selection allows the pre-selection of trait years before they can be evaluated in the field; this saves time and space in the development of new cultivars and allows selection to be focused on genotypes that carry appropriate alleles that will be passed on to descendants. Most of the research done with MAS in Prunus has been focused on developing scion cultivars, mostly in peach. The peach is one of the best genetically characterized species in the family Rosaceae (Abbott et al., 2002; Shulaev et al., 2008), not only for its economic importance but because of its small genome size. The first version of its genome sequence was published in 2010 in the Genome Database for Rosaceae (GDR) website (www.rosaceae.org) where information can also be obtained on the genetic and genomic resources of the different genera of Rosaceae (Jung et al., 2008; 2014). In 2013, the International Peach Genome Initiative published the peach genome sequence (Verde et al., 2013), and version 2.0 (Peach v2.0) of the genome is currently available at Phytozome (http:// phytozome.jgi.doe.gov/pz/portal.html\#! info?alias=Org Ppersica_er), Istituto di Genomica Applicata (IGA, Udine, Italy; http://services.appliedgenomics.org/fgb2/ iga/prunus_persica_v2/gbrowse/prunus_persica_v2/) and GDR (https://www.rosaceae.org/species/prunus_persica/ genome_v2.0.a1).

Knowledge about genome sequences of species of the family Rosaceae (available on GDR web page) has confirmed the level of synteny among genomes (Zhebentyayeva et al., 2008; Velasco et al., 2010; Shulaev et al., 2011; Verde et al., 2013) of this taxon. A degree of microsynteny had previously been confirmed between the bacterial artificial chromosome (BAC) sequences of Prunus and the Arabidopsis genome, as well as between Prunus BACs and the complete or partial genomes of other model species, such as Populus and Medicago (Jung et al., 2009). Synteny appears to be greater between Prunus and Populus than between Prunus and Medicago even though Medicago is evolutionarily closer to Prunus. These synteny analyses provide an opportunity to study the relationships between the structure and function of genomes of interest and facilitate map saturation with markers that are shared between species and identify genes in less studied organisms, such as Prunus. The first comparative genomic analysis of Rosaceae was published in 2011 (Illa et al., 2011b) using information about markers developed in this study and located in the genomes of Fragaria, Malus, and Prunus. Clear syntenic blocks were observed in the family, and an ancestral hypothetical genome was constructed that had nine chromosomes. Taking this into consideration, available information on markers and genes in these species will allow the identification of homologous species in those genomes that have not yet been sequenced; this will allow a more rapid and precise parallel advance in breeding programs by using available detailed information about each one of them.

\section{Molecular markers}

There are three main types of markers: (i) morphological, also called classical or visible, which are phenotypic traits, (ii) biochemical, which are mostly isoenzymes, and (iii) molecular (or DNA), which are DNA sequences that have single-nucleotide polymorphisms (SNPs) or insertion/ deletion (INDEL) polymorphisms that can be detected or identified by various techniques based on polymerase chain reaction (PCR), sequencing, or hybridization (Winter and Kahl, 1995; Jones et al., 1997; 2009). Molecular 
markers are the most widely used, mainly because they are abundant and not affected by environmental factors or the developmental or physiological state of the plant (Winter and Kahl, 1995).

Molecular markers have become a very important tool in plant breeding because of their usefulness in characterizing regions of the genome related to both qualitative and quantitative traits. They have allowed the deduction of the genome structures of a number of species, including fruit such as peach, apple, and strawberry (Zhebentyayeva et al., 2008; Velasco et al., 2010; Shulaev et al., 2011; Verde et al., 2013), as well as the determination of their sequences and genetic map locations.

Microsatellites (Litt and Luty, 1989) or simple sequence repeat (SSR; Tautz et al., 1986) are among the most used markers; they are sequences of 2 to $6 \mathrm{bp}$ (Chambers and MacAvoy, 2000) repeated in tandem that are frequently detected in prokaryote and eukaryote genomes (Kalia et al., 2011; Zane et al., 2002). They are found in both coding and non-coding regions and distributed throughout the genome. The characteristics of microsatellite sequences have made them the molecular marker of choice for many types of studies because of their high polymorphism and ability to identify both alleles in diploid organisms and given that they are co-dominant. They are very useful in identifying individuals propagated sexually or vegetatively since it is very improbable that two randomly selected individuals will have exactly the same alleles if several markers are used (Parida et al., 2009; Kalia et al., 2011). These markers have been widely used for the molecular characterization of scion cultivars of Prunus species (Cantini et al., 2001; Dirlewanger et al., 2002; Aranzana et al., 2003a; Struss et al., 2003; Pedersen, 2006; Rojas et al., 2008; Akpinar et al., 2010; Maghuly and Laimer, 2011) and rootstock cultivars (Serrano et al., 2002; Struss et al., 2002; Liu et al., 2007; Turkoglu et al., 2010; Arismendi et al., 2012). Arismendi et al. (2012) analyzed 26 commercial Prunus rootstocks used in Chile that belong to the subgenera Amygdalus (peaches), Prunus (plums), and Cerasus (cherries). They found the highest genetic diversity in Cerasus, followed by Prunus and Amygdalus. They also indicated that the 26 studied genotypes could be identified with a minimum of three microsatellite markers (PMS-3, BPPCT-037, and BPPCT-036); this is important information for characterizing germplasm used in a breeding program and confirming the identity of individuals from interspecific crosses.

The highest genetic diversity found among individuals of the subgenus Cerasus, described by Arismendi et al. (2012), can be explained by the self-incompatibility system found in some members of the family Rosaceae. These species have a gametophytic self-incompatibility system controlled by the multi-allelic locus $S$, which does not allow a plant to be fertilized by its own pollen or by that of closely related individuals (De Nettancourt, 2001). Thus, in these species, plants must be cross-pollinated to produce fruit. The self-incompatibility reaction is triggered when the $S$ gene is expressed in the pollen ( $S F B$ gene) and pistil ( $S$-RNasa gene), which stops pollen tube growth. Knowledge of the genetic and molecular bases of the self-incompatible reaction has allowed the application of molecular techniques such as PCR amplification of $S$ alleles with consensus or specific primers that amplify the two introns, which are part of the sequence of the S-RNasa gene (Tao et al., 1999; Tobutt et al., 2001; Wiersma et al., 2001; Sonneveld et al., 2001; 2003; Wünsch and Hormaza, 2004; 2005; Sonneveld et al., 2006), or amplify regions of the $S F B$ gene (Sonneveld et al., 2005). The peach is self-fertile; in contrast, most cultivated Prunus species, such as cherry, almond, plums, and apricot, are self-infertile and therefore self-incompatible. Due in part to self-incompatibility, genetic diversity is higher in self-infertile cultivar species than in peach (Mnejja et al., 2010). Knowledge of the $S$ genotypes of each cultivar has been useful for selecting appropriate pollen donors in commercial orchards and in breeding programs to ensure fruit production. Identification of the $S$ genotype of Prunus rootstocks would allow these to be distinguished one from the other, be used as a tool to confirm hybridization in the process of obtaining new interspecific hybrid individuals, and as a complement to analysis performed with microsatellite markers.

Single-nucleotide polymorphisms are the most common type of variation found in DNA (Brookes, 1999), and they are valuable markers for high-resolution genetic mapping, genetic variation studies, and association mapping in plants. A number of methods to identify SNPs have been described (Ganal et al., 2009): by searching expressed sequence tag (EST) databases (Batley et al., 2003), amplicon re-sequencing (Choi et al., 2007), complete sequence of a genome (Velasco et al., 2007), and more recently, high throughput sequencing technology (Barbazuk et al., 2007). Advances in next-generation techniques have reduced the cost of DNA sequencing to the point where it is now feasible to perform genotypingby-sequencing (GBS) to analyze small- and large-sized genomes with high diversity and allow the identification of thousands of markers for a species (Elshire et al., 2011; Poland et al., 2012; Ward et al., 2013; Guajardo et al., 2015). Future applications of GBS in genetic improvement will allow breeders to perform genomic selection of new germplasm or species without having to first develop a molecular tool, which is needed with other types of molecular markers; it will also allow conservation biologists to determine population structure without needing previous knowledge of the genome or diversity of the species under study (Elshire et al., 2011).

Genetic improvement and commercialization of rootstocks requires precisely identifying all available material since it is very difficult to observe the 
morphological traits of rootstocks after they have been grafted. Furthermore, most traits of interest in rootstocks are strongly influenced by the environment and the developmental stage of the plant (Casas et al., 1999). A combination of markers, such as microsatellites and $S$ haplotypes, to characterize the material used in a rootstock breeding program will benefit the precision of the program.

\section{Construction of genetic maps}

There are two basic map variants designed to assign a physical location to markers and genes in the genome: linkage maps, defined in units of recombination frequency, and physical maps in which the distance between loci is the physical or nucleotide distance. Genetic maps allow the locations of QTLs to be established as well as the eventual position of specific genes related to or responsible for the expression of any character. The possibility of using markers to tag these genes is based on the probability that two loci (markers or genes) are transmitted together from parents to offspring, which in turn, directly depends on the distance between them along the chromosome. For heterozygous species, such as Prunus spp., segregating populations are based on parents with phenotypes that are not necessarily contrasting for the trait under study, but which show segregation in the progeny.

The development of linkage maps for annual crops, such as corn and rice, began several years before it started in Prunus (Gardiner et al., 1993; Gowda et al., 2003) and other woody species; thus, MAS is already being used in these annual species mainly to detect pathogen resistance (Choudhary et al., 2008). Because fruit trees have a long juvenile period, some species are self-incompatible and trees are large, the development of molecular markers has taken more time. This is true not only for scion cultivars but mainly for rootstocks where marker availability is very scarce. The number of markers required to construct a map varies and depends on the number of chromosomes of the species; more markers are needed for species with larger genomes (Mohan et al., 1997). Molecular markers closely linked to QTLs can potentially be used in MAS in which selection is based more on DNA polymorphisms than on phenotypic variants (Zhang et al., 2010). Most of the information related to the DNA markers that have been used in Prunus, generated maps and identified QTLs and genes, is available in the Genome Database for Rosaceae (GDR) (www.rosaceae.org).

The genetic map published by Joobeur et al. (1998) is considered as the reference map for the genus Prunus. The analysis of $75 \mathrm{~F}_{2}$ individuals of a cross between almond 'Texas' and peach 'Earlygold' resulted in what is known as the $\mathrm{T} \times \mathrm{E}$ map. It was initially constructed with 246 markers (235 RFLPs and 11 isozymes) and covered a total distance of $491 \mathrm{cM}$ with a mean density of $2 \mathrm{cM}$ per marker. This map was compared with the one published previously for almond (Viruel et al., 1995); it was observed that the two maps were homologous or syntenic and the the markers were distributed in eight linkage groups. The $\mathrm{T} \times \mathrm{E}$ cross provided a highly polymorphic population for linkage studies, allowed the establishment of a common terminology for the linkage groups, and provided a set of markers with known positions that could be transferred to other species of the genus.

Using the information found on the $\mathrm{T} \times \mathrm{E}$ map, other maps were constructed and genetic analyses were performed that were associated with agronomic traits in almond populations (Joobeur et al., 2000; Ballester et al., 2001), almond $\times$ peach (Jáuregui et al., 2001; Bliss et al., 2002), apricot (Vilanova et al., 2003; Lambert et al., 2004), and peach (Dettori et al., 2001; Yamamoto et al., 2001; Etienne et al., 2002; Foulongne et al., 2003). However, the use of these maps is limited in Prunus because most were constructed with RFLPs that require complex and laborious laboratory procedures. The low genetic variability in species such as peach and to some extent, in apricot (Byrne, 1990) also limited the use of these markers. Given their high polymorphism, codominant inheritance, and the simplicity of the methods used to develop them, microsatellites, or simple sequence repeat (SSR), appeared as appropriate markers (Morgante and Olivieri, 1993). Many of these were developed in peach (Cipriani et al., 1999; Sosinski et al., 2000; Testolin et al., 2000; Aranzana et al., 2002; Dirlewanger et al., 2002) and cherry (Downey and Iezzoni, 2000; Cantini et al., 2001). By collecting all the available information, Aranzana et al. (2003b) analyzed 109 SSRs developed in peach and cherry by different research groups and mapped 96 of them on the Prunus reference map (Joobeur et al., 1998). This contribution brought the $\mathrm{T} \times \mathrm{E}$ map to a total of 342 markers, 105 of which were SSRs that had a total length of $522 \mathrm{cM}$.

Dirlewanger et al. (2004) published one of the key studies in the genomics of Prunus species. In their work, 220 additional markers were positioned on the $\mathrm{T} \times \mathrm{E}$ map (89 SSRs, 5 ESTs, and 126 RFLPs obtained mainly by using Arabidopsis thaliana primers, which were highly conserved compared with rice sequences [Domínguez et al., 2003]); they also compared the species of the genus using anchor markers. The $\mathrm{T} \times \mathrm{E}$ map was thus expanded to 562 markers covering $519 \mathrm{cM}$ with a mean density of $0.92 \mathrm{cM}$ per marker; $87 \%$ of the loci corresponded to known DNA sequences and $37 \%$ of these were associated with a putative protein. Comparing the positions of the anchor markers of the T $\times E$ map (RFLPs, SSRs, and isoenzymes) with those of maps constructed with other Prunus populations (Viruel et al., 1995; Joobeur et al., 2000; Ballester et al., 2001; Jáuregui et al., 2001; Dettori et al., 2001; Yamamoto et al., 2001; Etienne et al., 2002; Bliss et al., 2002; Vilanova et al., 2003; Foulongne et al., 2003; Lambert et al., 2004), it was found that the genomes of the diploid $(2 n=16)$ species peach, almond, apricot, cherry, $P$. davidiana (Carrière) N.E. Br., P. cerasifera, 
and P.ferganensis (Kostov \& Rjabov) Kovalev \& Kostov are essentially co-linear; it was therefore concluded that the genus Prunus can be treated as a single genetic unit. Given this high degree of molecular marker transferability among members of Rosaceae, rootstock breeding programs can also use markers from other Prunus species.

In recent years, new and more complete linkage maps have been developed for species in the genus Prunus. Saturation of the $\mathrm{T} \times \mathrm{E}$ map has been further increased with different types of markers and the identification of markers closely linked to traits that are important for genetic improvement. Research also continues to identify candidate genes responsible for traits of agronomic interest and to develop more genomic tools, such as physical mapping and identification of the positions of large collections of ESTs on the reference map. The study by Howad et al. (2005) increased the SSR markers in the T $\times$ E map from 185 to 449 by a strategy known as bin mapping (Vision et al., 2000). With this strategy, a normal-sized mapping population (60-250 individuals) can be used to construct a saturated map with markers located with high precision; new markers can later be added to the map with less precision using a subgroup of highly informative plants. The study by Howad et al. (2005) used 'Earlygold', the $\mathrm{F}_{1}$ hybrid, and six trees of the $\mathrm{T} \times \mathrm{E}$ population; it allowed new markers to be located within a chromosome fragment with a mean size of 7.8 $\mathrm{cM}$. After this study, the $\mathrm{T} \times \mathrm{E}$ map contained 826 markers; considering that the total map distance covered is $524 \mathrm{cM}$ (Dirlewanger et al., 2004; Howad et al., 2005), the marker coverage has a mean density of $0.63 \mathrm{cM}$ per marker.

Genetic maps developed in recent years have incorporated SNPs because they have fewer detection and evaluation errors than microsatellites, and it is possible to map QTLs with greater precision than other types of markers (Ball et al., 2010; Yu et al., 2011). An example is the study by Martínez-García et al. (2013) in which maps were constructed for two peach populations. There was a previous map for one population (intraspecific population Pop-DG from a cross between the non-melting flesh 'Dr. Davis' and the fresh consumption peach 'Georgia Belle') (Ogundiwin et al., 2009). In this new study, 1536 SNPs were evaluated with a genotyping assay (GoldenGate, Illumina, San Diego, California, USA) that allowed mapping 738 SNPs in the Pop-DG population and 1037 in the Pop-DF population. A consensus map was constructed with 588 SNPs covering $454 \mathrm{cM}$ and with a mean distance of $0.81 \mathrm{cM}$ between markers. The International Peach SNP Consortium (IPSC) developed a chip for this species consisting of 8144 SNPs, which was validated by 709 peach accessions and identified 6869 polymorphisms (Verde et al., 2012). Pirona et al. (2013) used this chip to analyze the $\mathrm{F}_{2}$ PI91459 ('NJ Weeping' $\times$ 'Bounty') population ( $\mathrm{W} \times \mathrm{By}, 103$ individuals), which led to the identification of a candidate gene that appears to control maturation date in peach, while Eduardo et al. (2013) and
Sánchez et al. (2014) used the chip to identify QTLs for fruit volatile organic compounds in peach. A chip is also available for cherry with 5696 SNPs, which was validated by evaluating 269 cherry and 330 sour cherry accessions (Peace et al., 2012). This chip was used by Klagges et al. (2013) to construct maps of two cherry populations, that is, 'Black Tartarian' $\times$ 'Kordia' $(\mathrm{BT} \times \mathrm{K})$ with 89 individuals and 'Regina' $\times$ 'Lapins' $(\mathrm{R} \times \mathrm{L})$ with 121 individuals. Results included 723 and 687 markers mapped in eight linkage groups on the $\mathrm{BT} \times \mathrm{K}$ and $\mathrm{R} \times \mathrm{L}$ maps, respectively. The maps covered $752.9 \mathrm{cM}$ for $\mathrm{BT} \times \mathrm{K}$ and $639.9 \mathrm{cM}$ for $\mathrm{R} \times \mathrm{L}$ with mean distances of 1.1 and $0.9 \mathrm{cM}$ per marker, respectively.

Each genetic map is unique and is the product of the characteristics provided by the parents of the mapping population and the type of markers used. Although the same group of markers is used to construct maps, there is no guarantee that all the markers will be polymorphic in populations with different progenitors. That is why common markers, or anchors, are needed to correlate information between two maps. Because it is essential to know the real location of markers when they are used to locate QTLs in a genetic map, it is important that the positions of discordant markers be confirmed in the construction of new maps to detect possible chromosome rearrangements or the existence of duplicated loci in the genome. It is also necessary to have more well-distributed markers in the linkage groups of each species to ensure marker availability to select polymorphic loci in the study population and construct new maps.

\section{Identification of QTLs and genes}

Quantitative trait loci and major genes are based on the association of a particular phenotypic trait with a DNA region (genotype) (Salazar et al., 2014). Many of these traits have quantitative inheritance, which is frequently controlled by multiple genes and/or influenced by the environment. To identify genes responsible for expressing a characteristic by the candidate gene approach (Pflieger et al., 2001), it is necessary to identify and map DNA sequences related to structural or regulatory genes whose biological function is known to affect the character of interest. If the map positions of these sequences colocalize with those of the main genes or QTLs for this character, a cause-effect relationship between DNA sequences and specific phenotypes can be demonstrated, for example, by finer mapping.

As mentioned above, the objective of constructing and saturating genetic maps is to more precisely locate genes and QTLs that could explain the expression of traits of interest. Using information from available maps, a number of groups have investigated QTLs and genes that are responsible for fruit characteristics and stress resistance, but there is still no available information to identify QTLs in Prunus rootstocks. Dirlewanger et al. (2006) compiled the information already published for 
all SSR markers as well as EST-SSRs and AFLPs; they constructed a new version of the map that this group had published in 1998 ('Ferjalou Jalousia' $\times$ 'Fantasia', or $\mathrm{J} \times \mathrm{F}$ map) (Dirlewanger et al., 1998) in which they had identified QTLs associated with fruit quality in peach (Dirlewanger et al., 1999). The number of $F_{2}$ progeny was increased to 207 individuals, which were segregated for five traits reported as Mendelian; they also found a new character which they called aborting fruit $(A f)$. All the Mendelian agronomic traits were located in the linkage map and SSR or AFLP markers associated with each of them were found. The marker associated with the Af trait allowed an early identification of individuals that would have problems at the productive stage, which is one of the objectives of MAS. Boudehri et al. (2009), using the same $\mathrm{F}_{2}$ population and fine mapping of a locus, subsequently reported the first description of the genes involved in a fruit quality character of a perennial tree. They developed 1024 combinations of AFLP primers tightly linked to the $D$ locus that controls fruit acidity. The recording of phenotypes of individuals that showed recombination linked to this locus led to its precise location within a $0.4 \mathrm{cM}$ interval. Prior to this study, very few fine genetic maps using a large number of trees had been published, and only pathogen-resistance genes had been analyzed (Lu et al., 1998; Claverie et al., 2004); thus, the detailed genetic and physical characterization of the $D$ locus was described as the first step toward isolating the gene or genes involved in peach fruit acidity.

Sequencing of cDNA libraries, obtained from the mRNA of a tissue, is another common strategy to identify genes being transcribed under a given condition. Le Dantec et al. (2010) used the progeny of the $\mathrm{J} \times \mathrm{F}$ mapping in peach (Dirlewanger et al., 2006) and the diploid set of bin mapping of Fragaria (Sargent et al., 2008) to identify candidate genes involved in the organoleptic quality of peach fruit and perform syntenic analysis between two genera, which can be expressed as the conservation or coherence of markers and genes and their order on the chromosomes of different genomes. They constructed two cDNA libraries from fruits of 'Fantasia' at two stages of development (Dirlewanger et al., 1998; Dirlewanger et al., 2006). These libraries were used to generate a set of EST sequences known as PeachESTdb. A total of 1730 peach unigenes were obtained after assembling the raw data along with 59 candidate genes that were selected because they were potentially involved in the sweetness, acidity, or phenolic content of the fruit or in fruit growth and development. Fifty-four pairs of primers designed from the candidate genes and producing PCR products in peach were tested in strawberry; 36 pairs of primers produced amplicons in the latter species, which provided a source of candidate genes that could be used with other species of Rosaceae. Eight candidate genes were mapped in peach, 14 in strawberry, and four in both species, confirming the synteny model proposed by other groups using comparative mapping. Various co-localizations between candidate genes and QTLs were mapped, this must be the object of further research to define the possible roles of these genes in the corresponding traits.

Another research group (Eduardo et al., 2010) used two progenies from peach crosses to search for QTLs related to fruit quality characteristics. One population was an $F_{1}$ population of 'Bolero' $(B) \times$ 'OroA' $(\mathrm{O})$ with 129 individuals. The other population included $169 \mathrm{~F}_{2}$ individuals from 'Contender' (C) $\times$ 'Ambra' (A). The B map consisted of 26 SSRs and a cleaved amplified polymorphic sequence (CAPS) that covered $255.4 \mathrm{cM}$, or $49.2 \%$ of the $\mathrm{T} \times \mathrm{E}$ map coverage; the $\mathrm{O}$ map consisted of $16 \mathrm{SSRs}$ and covered $129.9 \mathrm{cM}(25 \%$ of $\mathrm{T} \times \mathrm{E}$ map). Both populations were analyzed phenotypically for $2 \mathrm{yr}$ to evaluate maturation date, fruit weight, fruit epidermis color, total juice soluble solids, acidity, and pH. Data at flowering time and flower type were only analyzed in $\mathrm{B} \times \mathrm{O}$ for one $\mathrm{yr}$. One or two QTLs were detected per character in each population; most were localized in the same region forming QTL clusters, especially in linkage group 4. This was likely caused by a pleiotropic effect of the maturation date masking the identification of other QTLs for different traits, although it is more probable that it was due to the low map densities obtained. The authors recommended pedigree analysis based on molecular markers to better select the parents included in producing a population to improve the degree of heterozygosity in $\mathrm{F}_{1}$ populations and ensure a large number of polymorphisms in $\mathrm{F}_{2}$ populations in peach breeding programs (Eduardo et al., 2010).

In addition to developing maps to identify the genes responsible for characteristics related to fruit quality, there is interest in identifying genes involved in the response to different types of stress. To facilitate the mapping of genes that control chilling injury, which is a physiological disorder appearing at post-harvest stages in peach, Ogundiwin et al. (2008) developed the ChillPeach database consisting of 7862 ESTs and 4468 unigenes obtained from the mesocarp tissue of two progenies with contrasting tolerances to chilling injury. The datasets contained various putative SNPs and 184 unigenes with high-quality SSRs, $42 \%$ of which were new for Prunus. They used microarrays that contained 4261 ChillPeach unigenes; the analysis and posterior quantitative RT-PCR (qRT-PCR) for 13 selected genes indicated that ChillPeach is rich in genes that are specific to the fruit and induced by cold; this demonstrates the usefulness of this database for transcriptomic analysis in peach. This research group (Ogundiwin et al., 2009) subsequently constructed a linkage map with 211 markers (three morphological markers, 11 candidate genes related to maturation, and 13 cold-response genes), 21 new EST-SSRs from the ChillPeach database (Ogundiwin et al., 2008), and 58 previously reported SSRs, among others; they reported the mapping of genes that were hypothetically related to 
texture, pigmentation, taste, and cold response in peach fruit. They used intraspecific progeny called Pop-DG from the cross of a non-melting flesh peach 'Dr. Davis' and the melting flesh 'Georgia Belle'. The Pop-DG map covered $818 \mathrm{cM}$ of the peach genome and had a mean distance of $4 \mathrm{cM}$ between markers; this map was colinear with the Prunus reference map (Joobeur et al., 1998; Dirlewanger et al., 2004), with 39 common SSR markers. Likewise, the bin-mapping strategy was used in the $\mathrm{T} \times \mathrm{E}$ population with DNA from the same individuals found in the study by Howad et al. (2005), who mapped another 159 markers on the reference map: 59 candidate genes related to maturation, 50 cold-response genes, and 50 new EST-SSRs from the ChillPeach database: their locations were deduced from the Pop-DG map by comparative mapping. Various candidate genes and EST-SSRs were co-localized with loci for the main genes and QTLs for cold damage systems in the PopDG map. The usefulness of this "genetic map of fruit quality" is the co-localization of QTLs related to fruit quality with candidate genes on the same map, which is very important for understanding the genetic control of important production traits.

It is well known that winter chilling together with adequate heat accumulation determines the flowering date of a given cultivar (Sherman and Beckman, 2003). Fan et al. (2010) used an $F_{2}$ population of 378 peach trees from a cross between two genotypes with contrasting chilling requirements to construct a linkage map and chart QTLs. The map included 96 SSRs (36 shared with the T $\times$ E map), 30 AFLPs, and one morphological marker in eight linkage groups covering $535 \mathrm{cM}$, with a mean distance of $4.2 \mathrm{cM}$ between markers. The chilling and heat requirements of each genotype's flower buds were evaluated for 2 yr and flowering dates were recorded for $4 \mathrm{yr}$. Twenty QTLs with additive effects were identified for three traits, including a main QTL for the chilling requirement and two main QTLs for the flowering date. Most QTLs were co-localized with QTLs for other traits; therefore, either there is close linkage between genes that regulate different traits or genes have pleiotropic effects. This first report on mapping QTLs for the chilling requirement for flowering will facilitate MAS of cultivars that require little chilling and also help to identify and understand the genes that control the chilling requirement. It has been suggested that there may be a single temperature sensor and an action system regulating both the chilling and heat requirement for the flowering date (Fan et al., 2010).

Mnejja et al. (2010) used available information on genetic maps for species of the family Rosaceae to study 145 pairs of SSR primers and determine their transferability in eight cultivars of nine Rosaceae species (almond, peach, apricot, plum, prune, cherry, apple, pear, and strawberry). Of these markers, 25 came from almond genomic DNA (Mnejja et al., 2005), 22 from almond ESTs, 25 from peach genomic DNA (Dirlewanger et al.,
2002; Le Dantec et al., 2010), 25 were ESTs isolated from peach, and 25 were from plum genomic DNA (Mnejja et al., 2004). The remaining 23 markers were from apricot (13 ESTs and 10 genomic) (Hagen et al., 2004). These markers were all polymorphic in their respective species. Most primers $(83.6 \%)$ amplified segments of the expected size range in other Prunus species. Their transferability, which is the proportion of microsatellites that were amplified and polymorphic, was also high in Prunus (63.9\%). Thirty-one SSRs were amplified and polymorphic in all the studied species of Prunus; 12 of these were distributed over the entire genome and proposed as the "universal Prunus set" that could be useful for comparative studies and constructing linkage maps with common markers. In contrast, only $16.3 \%$ of all the studied SSRs were transferable to species of other Rosaceae genera (apple, pear and strawberry), which confirms the necessity or convenience of using other types of markers for genetic studies between genera.

Illa et al. (2011a) selected 273 sequences from EST collections that were candidate genes of metabolic pathways affecting growth and certain fruit traits, such as maturity, texture, sugar and organic acid content, aroma, and color, these were all mapped in the Prunus reference map. They used the bin-mapping strategy with the same eight trees used in previous studies (Howad et al., 2005; Ogundiwin et al., 2009). This strategy proved to be very efficient because it allowed mapping 206 candidate genes mainly based on segregating one or more SNPs. These candidate genes were distributed throughout the Prunus genome and provided a new resource for genetic analysis in the different species of the genus. The total number of candidate genes localized by bin-mapping in the T $\times E$ map was increased to 314 with this study; these genes could determine the genetic base of fruit quality in Prunus, which is the key information for breeding these species.

The identification of hypoxia-tolerant genes of Prunus rootstocks is being studied at the Centro de Estudios Avanzados en Fruticultura (CEAF) in Chile. Almada et al. (2013) published the identities of hypoxia-tolerant genes, which were class 1 non-symbiotic $\mathrm{Hb}$-like (nsHb) and class 3 truncated $\mathrm{Hb}$-like ( $\mathrm{trHb}$ ). Although the putative genes $n s \mathrm{Hb}$ and $\mathrm{trHb}$ were induced by hypoxia in the roots of all analyzed genotypes of Prunus, independently of their tolerance to hypoxia, they observed that expression levels were higher in the tolerant rootstocks. They found that other abiotic stresses, such as salt stress and low temperature stress, are also regulated by these genes. Arismendi et al. (2015) performed transcriptomic sequencing of two Prunus rootstocks, 'Mariana 2624' and 'Mazzard F12/1', which are tolerant and sensitive to hypoxia, respectively, to identify candidate genes involved in the response to root hypoxia. They identified a group of differentially expressed genes exclusively upregulated in the tolerant genotype, which are associated with enzymes of posttranslational protein modifications. 
Their results represent a valuable source of information for further studies to identify the mechanism and genes that define hypoxia tolerance in Prunus.

\section{CONCLUSIONS}

The practical purpose of developing markers and genetic maps, as well as sequencing the complete genomes of a number of species, is to help understand gene locations, which is a basic platform for subsequent development to understand their function, regulation, and expression, especially for genes responsible for traits of agronomic interest in breeding programs. Chromosomal positions of disease resistance and fruit quality genes have been identified using available information about markers and genetic maps. Markers associated with these genes have also been identified, which can be used in breeding programs for early selection to produce new cultivars with desirable traits.

The development of higher density maps will provide researchers with a wide variety of tools for QTL mapping and markers for MAS.Unfortunately, available information about some species, such as cherry, and Prunus rootstocks is still limited; comparative mapping has become and will continue to be a widely used technique. The gaining of knowledge about gene sequences of species such as peach, apple, and strawberry will promote research of other species of the family Rosaceae given the high colinearity among their genomes.

\section{ACKNOWLEDGEMENTS}

We thank CONICYT-REGIONAL/GORE O’HIGGINS/ CEAF/R08I1001 for financial assistance, and CONICYT Fellowship for Thesis Implementation Support 2012 for VG.

\section{LITERATURE CITED}

Abbott, A., L. Georgi, D. Yvergniaux, Y. Wang, A. Blenda, G. Reighard, et al. 2002. Peach: The model genome for Rosaceae. Acta Horticulturae 575:145-155.

Akpinar, A.K., H. Koçal, A. Ergül, K. Kazan, M.E. Şelli, M. Bakir, et al. 2010. SSR-based molecular analysis of economically important Turkish apricot cultivars. Genetics and Molecular Research 9:324-332.

Almada, R., M.J. Arismendi, P. Pimentel, P. Rojas, P. Hinrichsen, M. Pinto, et al. 2013. Class 1 non-symbiotic and class 3 truncated hemoglobin-like genes are differentially expressed in stone fruit rootstocks (Prunus L.) with different degrees of tolerance to root hypoxia. Tree Genetics \& Genomes 9:1051-1063.

Aranzana,M.J.,J.Carbó, and P.Arús. 2003a. Microsatellite variability in peach [Prunus persica (L.) Batsch]: cultivar identification, marker mutation, pedigree inferences and population structure. Theoretical and Applied Genetics 106:1341-1352.

Aranzana, M.J., J. García-Mas, J. Carbó, and P. Arús. 2002. Development and variability analysis of microsatellite markers in peach. Plant Breeding 121:87-92.

Aranzana, M.J., A. Pineda, P. Cosson, E. Dirlewanger, J. Ascasibar, G. Cipriani, et al. 2003b. A set of simple-sequence repeat markers covering the Prunus genome. Theoretical and Applied Genetics 106:819-825
Arismendi, M.J., R. Almada, P. Pimentel, A. Bastias, A. Salvatierra, P. Rojas, et al. 2015. Transcriptome sequencing of Prunus sp. rootstocks roots to identify candidate genes involved in the response to root hypoxia. Tree Genetics \& Genomes 11:11.

Arismendi, M.J., P. Hinrichsen, R. Almada, P. Pimentel, M. Pinto, and B. Sagredo. 2012. Characterization of genetic diversity of stone fruit rootstocks used in Chile by means of microsatellite markers. Journal of the American Society for Horticultural Science 137(5):302-310.

Ball, A., J. Stapley, D. Dawson, T. Birkhead, T. Burke, and J. Slate. 2010. A comparison of SNPs and microsatellites as linkage mapping markers: lessons from the zebra finch (Taeniopygia guttata). BMC Genomics 11(1):218.

Ballester, J., R. Socias i Company, P. Arús, and M.C. de Vicente. 2001. Genetic mapping of a major gene delaying blooming time in almond. Plant Breeding 120:268-270.

Barbazuk, W.B., S.J. Emrich, H.D. Chen, L. Li, and P.S. Schnable. 2007. SNP discovery via 454 transcriptome sequencing. Plant Journal 51:910-918.

Batley, J., G. Barker, H. O'Sullivan, K.J. Edwards, and D. Edwards. 2003. Mining for single nucleotide polymorphisms and insertions/ deletions in maize expressed sequence tag data. Plant Physiology 132:84-91.

Beckman, T.G., and G.A. Lang. 2003. Rootstock breeding for stone fruits. Acta Horticulturae 622:531-551.

Bliss, F.A., S. Arulsekar, M.R. Foolad, V. Becerra, A.M. Gillen, M.L. Warburton, et al. 2002. An expanded genetic linkage map of Prunus based on an interspecific cross between almond and peach Genome 45:520-529.

Boudehri, K., A. Bendahmane, G. Cardinet, C. Troadec, A. Moing, and E. Dirlewanger. 2009. Phenotypic and fine genetic characterization of the $D$ locus controlling fruit acidity in peach. BMC Plant Biology 9:59-73.

Brookes, A.J. 1999. The essence of SNPs. Gene 234:177-186.

Byrne, D.H. 1990. Isozyme variability in four diploid stone fruits compared with other woody perennial plants. Journal of Heredity 81:68-71.

Cantini, C., A.F. Iezzoni, W.F. Lamboy, M. Boritzki, and D. Struss. 2001. DNA fingerprinting of tetraploid cherry germplasm using simple sequence repeats. Journal of the American Society for Horticultural Science 126:205-209.

Casas, A.M., E. Igartua, G. Balaguer, and M.A. Moreno. 1999. Genetic diversity of Prunus rootstocks analyzed by RAPD markers. Euphytica 110:139-149.

Chambers, G.K., and E.S. MacAvoy. 2000. Microsatellites: consensus and controversy. Comparative Biochemistry and Physiology. Part B, Biochemistry \& Molecular Biology 126:455-476.

Choi, I.Y., D.L. Hyten, L.K. Matukumalli, Q. Song, J.M. Chaky, C.V. Quigley, et al. 2007. A soybean transcript map: gene distribution, haplotype and single-nucleotide polymorphism analysis. Genetics 176:685-696.

Choudhary, K., O.P. Choudhary, and N.S. Shekhawat. 2008. Marker assisted selection: A novel approach for crop improvement. American-Eurasian Journal of Agronomy 1(2):26-30.

Cipriani, G., G. Lot, W.-G. Huang, M.T. Marrazzo, E. Peterlunger, and R. Testolin. 1999. AC/GT and AG/CT microsatellite repeats in peach [Prunus persica (L.) Batsch]: isolation, characterization and cross-species amplification in Prunus. Theoretical and Applied Genetics 99:65-72.

Claverie, M., E. Dirlewanger, P. Cosson, N. Bosselut, A.C. Lecouls, R. Voisin, et al. 2004. High resolution mapping and chromosome landing at the root know nematode resistance locus $M a$ from Myrobalan plum using a large-insert BAC DNA library. Theoretical and Applied Genetics 109:1318-1327.

De Nettancourt, D. 2001. Incompatibility and incongruity in wild and cultivated plants. $2^{\text {nd }}$ ed. 322 p. Springer-Verlag, Berlin, Heidelberg, Germany.

Dettori, M., R. Quarta, and I. Verde. 2001. A peach linkage map integrating RFLPs, SSRs, RAPDs, and morphological markers. Genome 44:783-790. 
Dirlewanger, E., P. Cosson, K. Boudehri, C. Renaud, G. Capdeville, Y. Tauzin, et al. 2006. Development of a second-generation genetic linkage map for peach [Prunus persica (L.) Batsch] and characterization of morphological traits affecting flower and fruit. Tree Genetics \& Genomes 3:1-13.

Dirlewanger, E., P. Cosson, M. Tavaud, M.J. Aranzana, C. Poizat, A. Zanetto, et al. 2002. Development of microsatellite markers in peach [Prunus persica (L.) Batsch] and their use in genetic diversity analysis in peach and sweet cherry (Prunus avium L.) Theoretical and Applied Genetics 105:127-138.

Dirlewanger, E., E. Graziano, T. Joobeur, F. Garriga-Caldere, P. Cosson, W. Howad, et al. 2004. Comparative mapping and marker assisted selection in Rosaceae fruit crops. Proceedings of the National Academy of Sciences of United States of America 101:9891-9896.

Dirlewanger, E., A. Moing, C. Rothan, L. Svanella, V. Pronier, A. Guye, et al. 1999. Mapping QTLs controlling fruit quality in peach (Prunus persica (L.) Batsch). Theoretical and Applied Genetics 98:18-31.

Dirlewanger, E., V. Pronier, C. Parvery, C. Rothan, A. Guy, and R. Monet. 1998. Genetic linkage map of peach. Theoretical and Applied Genetics 97:888-895.

Domínguez, I., E. Graziano, C. Gebhardt, A. Barakat, S. Berry, P. Arús, et al. 2003. Plant genome archaeology: Evidence for conserved ancestral chromosome segments in dicotyledonous plant species. Plant Biotechnology Journal 1:91-99.

Downey, S.L., and A.F. Iezzoni. 2000. Polymorphic DNA markers in black cherry (Prunus serotina) are identified using sequences from sweet cherry, peach, and sour cherry. Journal of the American Society for Horticultural Science 125:76-80.

Eduardo, I., G. Chietera, R. Pirona, I. Pacheco, M. Troggio, E. Banchi, et al. 2013. Genetic dissection of aroma volatile compounds from the essential oil of peach fruit: QTL analysis and identification of candidate genes using dense SNP maps. Tree Genetics \& Genomes 9:189-204.

Eduardo, I., I. Pacheco, G. Chietera, D. Bassi, C. Pozzi, A. Vecchietti, et al. 2010. QTL analysis of fruit quality traits in two peach intraspecific populations and importance of maturity date pleiotropic effect. Tree Genetics \& Genomes 7:323-335.

Elshire, R.J., J.C. Glaubitz, Q. Sun, J.A. Poland, K. Kawamoto, E.S. Buckler, et al. 2011. A Robust, simple genotyping-bysequencing (GBS) approach for high diversity species. PLoS ONE 6(5):e19379.

Etienne, C., C. Rothan, A. Moing, C. Plomion, C. Bodenes, L. Svanella-Dumas, et al. 2002. Candidate genes and QTLs for sugar and organic acid content in peach [Prunus persica (L.) Batsch]. Theoretical and Applied Genetics 105:145-159.

Fan, S., F. Bielenberg, T. Zhebentyayeva, G. Reighard, W. Okie, D. Holland, et al. 2010. Mapping quantitative trait loci associated with chilling requirement, heat requirement and bloom date in peach (Prunus persica). New Phytologist 185:917-930.

Foulongne, M., T. Pascal, P. Arús, and J. Kervella. 2003. The potential of Prunus davidiana for introgression into peach [Prunus persica (L.) Batsch] assessed by comparative mapping. Theoretical and Applied Genetics 107:227-238.

Ganal, M.W., T. Altmann, and M.S. Roder. 2009. SNP identification in crop plants. Current Opinion in Plant Biology 12:211-217.

Gardiner, J., S. Melia-Hancock, D.A. Hoisington, S. Chao, and E.H. Coe. 1993. Development of a core RFLP map in maize using an immortalized $\mathrm{F}_{2}$ population. Genetics 134:917-930.

Gowda, M., R.C. Venu, K. Roopalakshmi, M.V. Sreerekha, and R.S. Kulkarni. 2003. Advances in rice breeding, genetics and genomics. Molecular Breeding 11:337-352.

Guajardo, V., S. Solís, B. Sagredo, F. Gainza, C. Muñoz, K. Gasic, et al. Construction of high density sweet cherry (Prunus avium L.) linkage maps using microsatellite markers and SNPs detected by genotyping-by-sequencing (GBS). PLoS ONE 10(5):e0127750. doi:10.1371/journal.pone.0127750.
Hagen, L.S., J. Chaib, B. Fady, V. Decroocq, J.P. Bouchet, P. Lambert, et al. 2004. Genomic and cDNA microsatellites from apricot (Prunus armeniaca L.) Molecular Ecology Notes 4:742-745.

Howad, W., T. Yamamoto, E. Dirlewanger, R. Testolin, P. Cosson, G. Cipriani, et al. 2005. Mapping with a few plants: using selective mapping for microsatellite saturation of the Prunus reference map. Genetics 171:1305-1309.

Illa, E., I. Eduardo, J.M. Audergon, F. Barale, E. Dirlewanger, X. Li, et al. 2011a. Saturating the Prunus (stone fruits) genome with candidate genes for fruit quality. Molecular Breeding 28:667-682.

Illa, E., D.J. Sargent, E. Lopez Girona, J. Bushakra, A. Cestaro, R. Crowhurst, et al. 2011b. Comparative analysis of rosaceous genomes and the reconstruction of a putative ancestral genome for the family. BMC Evolutionary Biology 11:9-21.

Jáuregui, B., M.C. de Vicente, R. Messeguer, A. Felipe, A. Bonnet, G. Salesses, et al. 2001. A reciprocal translocation between 'Garfi' almond and 'Nemared' peach. Theoretical and Applied Genetics 102:1169-1176.

Jones, N., H. Ougham, and H. Thomas. 1997. Markers and mapping: We are all geneticists now. New Phytologist 137:165-177.

Jones, N., H. Ougham, H. Thomas, and I. Pasakinskiene. 2009. Markers and mapping revisited: finding your gene. New Phytologist 183:935-966.

Joobeur, T., N. Periam, M.C. de Vicente, G.J. King, and P. Arús. 2000. Development of a second generation linkage map for almond using RAPD and SSR markers. Genome 43:649-655.

Joobeur, T., M.A. Viruel, M.C. de Vicente, B. Jauregui, J. Ballester, M.T. Dettoni, et al. 1998. Construction of a saturated linkage map for Prunus using an almond $\times$ peach $\mathrm{F}_{2}$ progeny. Theoretical and Applied Genetics 97:1034-1041.

Jung, S., S.P. Ficklin, T. Lee, C.-H. Cheng, A. Blenda, P. Zheng, et al. 2014. The genome database for Rosaceae (GDR): year 10 update. Nucleic Acids Research 42: D1237-D1244.

Jung, S., D. Jiwan, I. Cho, T. Lee, A. Abbott, B. Sosinski, et al. 2009. Synteny of Prunus and other model plant species. BMC Genomics 10:76-92.

Jung, S., M. Staton, T. Lee, A. Blenda, R. Svancara, A. Abbott, et al. 2008. GDR (Genome Database for Rosaceae): integrated webdatabase for Rosaceae genomics and genetics data. Nucleic Acids Research 36:D1034-D1040.

Kalia, R., M. Rai, S. Kalia, R, Singh, and A. Dhawan. 2011. Microsatellite markers: an overview of the recent progress in plants. Euphytica 177:309-334.

Klagges, C., J.A. Campoy, J. Quero-García, A. Guzmán, L. Mansur, E. Gratacós, et al. 2013. Construction and comparative analyses of highly dense linkage maps of two sweet cherry intra-specific progenies of commercial cultivars. PLoS ONE 8(1):e54743.

Knapp, S.J. 1998. Marker-assisted selection as a strategy for increasing the probability of selecting superior genotypes. Crop Science 38:1164-1174.

Lambert, P., L. Hagen, P. Arús, and J. Audergon. 2004. Genetic linkage maps of two apricot cultivars (Prunus armeniaca L.) compared with the almond 'Texas' $x$ peach 'Earlygold' reference map for Prunus. Theoretical and Applied Genetics 108:1120-1130

Le Dantec, L., G. Cardinet, J. Bonet, M. Fouché, K. Boudehri, A. Monfort, et al. 2010. Development and mapping of peach candidate genes involved in fruit quality and their transferability and potential use in other Rosaceae species. Tree Genetics \& Genomes 6:995-1012.

Litt, M., and J.M. Luty. 1989. A hypervariable microsatellite revealed by in vitro amplification of a dinucleotide repeat within the cardiac muscle actin gene. American Journal of Human Genetics 44:397-401.

Liu, X., G.L. Reighard, G.A. Swire-Clark, and W.V. Baird. 2007. Peach rootstock identification by DNA-fingerprinting with microsatellite (SSR) markers. Journal of the American Pomological Society 61:162-166. 
Lu, Z.-X., B. Sosinski, G. Reighard, W. Baird, and A. Abbott. 1998. Construction of a genetic linkage map and identification of AFLP markers of resistance to root-knot nematodes in peach rootstocks. Genome 41:199-207.

Maghuly, F., and M. Laimer. 2011. Microsatellite variability between apricot and related Prunus species. BMC Proceedings 5(7):10-12.

Martínez-García, P.J., D.E. Parfitt, E.A. Ogundiwin, J. Fass, H.M. Chan, R. Ahmad, et al. 2013. High density SNP mapping and QTL analysis for fruit quality characteristics in peach (Prunus persica L.) Tree Genetics \& Genomes 9(1):19-36.

Mnejja, M., J. Garcia-Mas, J.M. Audergon, and P. Arús. 2010. Prunus microsatellite marker transferability across rosaceous crops. Tree Genetics \& Genomes 6:689-700.

Mnejja, M., J. Garcia-Mas, W. Howad, and P. Arús. 2005. Development and transportability across Prunus species of fortytwo polymorphic almond microsatellites. Molecular Ecology Notes 5:531-535.

Mnejja, M., J. Garcia-Mas, W. Howad, M.L. Badenes, and P. Arús. 2004. Simple-sequence repeat (SSR) markers of Japanese plum (Prunus salicina Lindl.) are highly polymorphic and transferable to peach and almond. Molecular Ecology Notes 4:163-166.

Mohan, M., S. Nair, A. Bhagwat, T.G. Krishna, M. Yano, C.R. Bhatia, et al. 1997. Genome mapping, molecular markers and markerassisted selection in crop plants. Molecular Breeding 3:87-103.

Moreno, M. 2004. Breeding and selection of Prunus rootstocks at the Aula Dei Experimental Station, Zaragoza, Spain. Acta Horticulturae 658:519-528.

Morgante, M., and A.M. Olivieri. 1993. PCR-amplified microsatellites as markers in plant genetics. Plant Journal $3: 175-182$

Ogundiwin, E.A., C. Martí, J. Forment, C. Pons, A. Granell, T.M. Gradziel, et al. 2008. Development of ChillPeach genomic tools and identification of cold-responsive genes in peach fruit. Plant Molecular Biology 68:379-397.

Ogundiwin, E., C. Peace, T. Gradziel, D. Parfitt, A. Bliss, and C. Crisosto. 2009. A fruit quality gene map of Prunus. BMC Genomics 10:587-600.

Parida, S., S. Kalia, K. Sunita, V. Dalal, G. Hemaprabha, A. Selvi, et al. 2009. Informative genomic microsatellite markers for efficient genotyping applications in sugarcane. Theoretical and Applied Genetics 118:327-338.

Peace, C., N. Bassil, D. Main, S. Ficklin, U.R. Rosyara, T. Stegmeir, et al. 2012. Development and evaluation of a genome-wide $6 \mathrm{~K}$ SNP array for diploid sweet cherry and tetraploid sour cherry. PLoS ONE 7(12):e48305.

Pedersen, B.H. 2006. DNA fingerprints of 51 sweet and sour Prunus accessions using Simple Sequence Repeats. Journal of Horticultural Science and Biotechnology 81:118-124.

Pflieger, S., V. Lefebvre, and M. Causse. 2001. The candidate gene approach in plant genetics: A review. Molecular Breeding 7:275-291

Pirona, R., I. Eduardo, I. Pacheco, C. Da Silva Linge, M. Miculan, I Verde, et al. 2013. Fine mapping and identification of a candidate gene for a major locus controlling maturity date in peach. BMC Plant Biology 13:166.

Poland, J.A., P.J. Brown, M.E. Sorrells, and J.L. Jannink. 2012. Development of high-density genetic maps for barley and wheat using a novel two-enzyme genotyping-by-sequencing approach. PLOS ONE 7(2):e32253.

Polidoros, A.N., P.V. Mylona, and B. Arnholdt-Schmitt. 2009. Aox gene structure, transcript variation and expression in plants. Physiologia Plantarum 137:342-353.

Potter, D., T. Eriksson, R.C. Evans, S. Oh, J.E.E. Smedmark, D.R. Morgan, et al. 2007. Phylogeny and classification of Rosaceae. Plant Systematics and Evolution 266:5-43.

Rojas, G., M. Méndez, C. Muñoz, G. Lemus, and P. Hinrichsen. 2008. Identification of a minimal microsatellite marker panel for the fingerprinting of peach and nectarine cultivars. Electronic Journal of Biotechnology 11(5):4-5.
Salazar, J.A., D. Ruiz, J.A. Campoy, R. Sánchez-Pérez, C.H Crisosto, P.J. Martínez-García, et al. 2014. Quantitative trait loci (QTL) and mendelian trait loci (MTL) analysis in Prunus: a breeding perspective and beyond. Plant Molecular Biology Reporter 32:1-18.

Sánchez, G., J. Martínez, J. Romeu, J. García, A.J. Monforte, ML. Badenes, et al. 2014. The peach volatilome modularity is reflected at the genetic and environmental response levels in a QTL mapping population. BMC Plant Biology 14:137.

Sargent, D.J., G. Cipriani, S. Vilanova, D. Gil-Ariza, P. Arús, D.W. Simpson, et al. 2008. The development of a bin mapping population and the selective mapping of 103 markers in the diploid Fragaria reference map. Genome 51:120-127.

Serrano, B., J. Gómez-Aparisi, and J.I. Hormaza. 2002. Molecular fingerprinting of Prunus rootstocks using SSRs. The Journal of Horticultural Science and Biotechnology 77:368-372.

Setter, T.L., and I. Waters. 2003. Review of prospects for germplasm improvement for waterlogging tolerance in wheat, barley and oats. Plant and Soil 253:1-34

Sherman, W.B., and T.G. Beckman. 2003. Climatic adaptation in fruit crops. Acta Horticulturae 622:411-428.

Shulaev, V., S.S. Korban, B. Sosinski, A.G. Abbott, H.S. Aldwinckle, K.M. Folta, et al. 2008. Multiple models for Rosaceae genomics. Plant Physiology 157:985-1003.

Shulaev, V., D.J. Sargent, R.N. Crowhurst, T.C. Mockler, O. Folkerts, A.L. Delcher, et al. 2011. The genome of woodland strawberry (Fragaria vesca). Nature Genetics 43:109-118.

Sonneveld, T., T. Robbins, R. Boskovic, and K. Tobutt. 2001. Cloning of six cherry self-incompatibility alleles and development of allele-specific PCR detection. Theoretical and Applied Genetics 102:1046-1055.

Sonneveld, T., T. Robbins, and K. Tobutt. 2006. Improved discrimination of self-incompatibility $S$-RNase alleles in cherry and high throughput genotyping by automated sizing of first intron polymerase chain reaction products. Plant Breeding 125:305-307.

Sonneveld, T., K. Tobutt, and T. Robbins. 2003. Allele-specific PCR detection of sweet cherry self-incompatibility $(S)$ alleles S1 to S16 using consensus and allele-specific primers. Theoretical and Applied Genetics 107:1059-1070.

Sonneveld, T., K. Tobutt, S. Vaughan, and T. Robbins. 2005. Loss of pollen-S function in two self-compatible selections of Prunus avium is associated with deletion/mutation of an $S$ haplotypespecific F-box gene. The Plant Cell 17:37-51.

Sosinski, B., M. Gannavarapu, L.D. Hager, L.E. Beck, G.J. King, C.D. Ryder, et al. 2000. Characterization of microsatellite markers in peach [Prunus persica (L.) Batsch]. Theoretical and Applied Genetics 101:421-428.

Struss, D., R. Ahmad, S. Southwick, and M. Boritzki. 2003. Analysis of sweet cherry (Prunus avium L.) cultivars using SSR and AFLP markers. Journal of the American Society for Horticultural Science 128:904-909.

Struss, D., M. Boritzki, R. Karle, and A. Iezzoni. 2002. Microsatellite markers differentiate eight Giessen cherry rootstocks. Horticultural Science 37:191-193.

Tao, R., H. Yamane, A. Sugiura, H. Murayama, H. Sassa, and H. Mori. 1999. Molecular typing of $S$-alleles through identification, characterization and cDNA cloning for $S$-RNases in sweet cherry. Journal of the American Society for Horticultural Science 124:224-233

Tautz, D., M. Trick, and G.A. Dover. 1986. Cryptic simplicity in DNA is a major source of genetic variation. Nature 322:652-656.

Testolin, R., T. Marrazzo, G. Cipriani, R. Quarta, I. Verde, M.T. Dettori, et al. 2000. Microsatellite DNA in peach (Prunus persica L. Batsch) and its use in fingerprinting and testing the genetic origin of cultivars. Genome 43:512-520.

Tobutt, K., R. Boskovic, and T. Sonneveld. 2001. Cherry (in) compatibility genotypes - harmonization of recent results from UK, Canada, Germany, Japan and USA. Eucarpia Fruit Breeding Section Newsletter 5:41-46. 
Turkoglu, Z., S. Bilgener, S. Ercisli, M. Bakir, A. Koc, M. Akbulut, et al. 2010. Simple sequence repeat-based assessment of genetic relationships among Prunus rootstocks. Genetics and Molecular Research 9:2156-2165.

Velasco, R., A. Zharkikh, J. Affourtit, A. Dhingra, A. Cestaro, A. Kalyanaraman, et al. 2010. The genome of the domesticated apple (Malus $\times$ domestica Borkh.) Nature Genetics 42(10):833-841.

Velasco, R., A. Zharkikh, M. Troggio, D.A. Cartwright, A. Cestaro, D. Pruss, et al. 2007. A high quality draft consensus sequence of the genome of a heterozygous grapevine variety. PLoS ONE 2(12):e1326.

Verde, I., A.G. Abbott, S. Scalabrin, S. Jung, S. Shu, F. Marroni, et al. 2013. The high-quality draft genome of peach (Prunus persica) identifies unique patterns of genetic diversity, domestication and genome evolution. Nature Genetics 45:487:496.

Verde, I., N. Bassil, S. Scalabrin, B. Gilmore, C.T. Lawley, K. Gasic, et al. 2012. Development and evaluation of a 9K SNP array for peach by internationally coordinated SNP detection and validation in breeding germplasm. PLoS ONE 7(4):e35668.

Vilanova, S., C. Romero, A. Abbott, G. Llacer, and M. Badenes. 2003. An apricot (Prunus armeniaca L.) $\mathrm{F}_{2}$ progeny linkage map based on SSR and AFLP markers, mapping plum pox virus resistance and self-incompatibility traits. Theoretical and Applied Genetics 107:239-247.

Vision, T.J., D.G. Brown, D.B. Shmoys, R.T. Durrett, and S.D. Tanksley. 2000. Selective mapping: a strategy for optimizing the construction of high-density linkage maps. Genetics 155:407-420.

Viruel, M., R. Messeguer, M. de Vicente, J. García-Mas, P. Puigdomenech, F. Vargas, et al. 1995. A linkage map with RFLP and isozyme markers for almond. Theoretical and Applied Genetics 91:964-971.

Ward, J.A., J. Bhangoo, F. Fernández-Fernández, P. Moore, J.D. Swanson, R. Viola, et al. 2013. Saturated linkage map construction in Rubus idaeus using genotyping by sequencing and genomeindependent imputation. BMC Genomics 14:2.
Wiersma, P., Z. Wu, L. Zhou, C. Hampson, and F. Kappe. 2001. Identification of new self-incompatibility alleles in sweet cherry (Prunus avium L.) and clarification of incompatibility groups by PCR and sequencing analysis. Theoretical and Applied Genetics 102:700-708.

Winter, P., and G. Kahl. 1995. Molecular marker technologies for plant improvement. World Journal of Microbiology and Biotechnology 11:438-448.

Wünsch, A., and J. Hormaza. 2004. Cloning and characterization of genomic DNA sequences of four self-incompatibility alleles in sweet cherry (Prunus avium L.) Theoretical and Applied Genetics 108:299-305.

Yamamoto, T., T. Shimada, T. Imai, H. Yaegaki, T. Haji, N. Matsuta, et al. 2001. Characterization of morphological traits based on a genetic linkage map in peach. Breeding Science 51:271-278.

Yu, H., W. Xie, J. Wang, Y. Xing, C. Xu, X. Li, et al. 2011. Gains in QTL detection using an ultra-high density SNP map based on population sequencing relative to traditional RFLP/SSR markers. PLoS ONE 6(3):e17595.

Zane, L., L. Bargelloni, and T. Patarnello. 2002. Strategies for microsatellite isolation: A review. Molecular Ecology 11:1-16.

Zhang, G., A.M. Sebolt, S.S. Sooriyapathirana, D. Wang, M.C. Bink, J.W. Olmstead, et al. 2010. Fruit size QTL analysis of an $F_{1}$ population derived from a cross between a domesticated sweet cherry cultivar and a wild forest sweet cherry. Tree Genetics \& Genomes 6:25-36.

Zhebentyayeva, T.N., G. Swire-Clark, L.L. Georgi, L. Garay, S. Jung, S. Forrest, et al. 2008. A framework physical map for peach, a model Rosaceae species. Tree Genetics \& Genomes 4:745-756.

Zhou, M. 2010. Improvement of plant waterlogging tolerance. p. 267-285. In Mancuso, S., and S. Shabala. (eds.) Waterlogging signalling and tolerance in plants. Springer-Verlag, Heidelberg, Germany. 